\title{
Rapid and safe direct cannulation of the true lumen of the ascending aorta in acute type $A$ aortic dissection
}

\author{
Heinz Jakob, MD, PhD, Konstantinos Tsagakis, MD, Andras Szabo, MD, Ingo Wiese, ECCP, Matthias Thielmann, MD, \\ and Ulf Herold, MD, Essen, Germany
}

I n acute type A aortic dissection (AADA), axillary artery cannulation has become a widely accepted arterial access for antegrade aortic and cerebral perfusion. However, in emergency situations with highly unstable hemodynamics or in cases of dissection extending into the innominate artery, another access has to be chosen. In the past, we as well as others ${ }^{1}$ have used direct ascending aortic cannulation based on the echocardiographic knowledge of free communication between the true and false lumina in the ascending aorta. However, in a few cases, neurologic outcome was not favorable, probably owing to dispersion of thrombotic material from the frequently cannulated false lumen. To solve this problem, we modified our technique of direct access to the ascending aorta.

\section{Clinical Summary}

From April 2006 until January 2007, a total of 11 patients with AADA were operated on on an emergency basis. In 8 patients, either pericardial tamponade with severe hemodynamic instability or dissection involving the innominate artery forced a modified approach from our standard right axillary artery cannulation site (Table 1).

After opening of the pericardium, a pursestring suture is placed to the right atrial appendage for venous cannulation. Immediate venous exsanguination to gravity into a standard integrated oxygenator reservoir with an intercept reservoir is started with the patient preoxygenated with $100 \%$ inspired oxygen fraction over several minutes. Within 45 seconds, 3.5 to 4.5 L of blood volume is withdrawn and the ascending aorta starts collapsing, indicating low cardiac filling. Arterial systolic pressure at that time is $30 \mathrm{~mm} \mathrm{Hg}$ or less. With the patient placed head down, a midaortic (usual adventitial) incision is made on the convex side of the ascending aorta with 1 or 2 suction devices in place (Figure 1, A). Usually, the true lumen sac is rapidly identified. In case the entry tear is located at this site, the true lumen is grasped with a DeBakey forceps and inspected. In case of an intact true lumen sac, a 2- to $3-\mathrm{cm}$ incision is made upstream for intraluminal inspection (Figure 1,

\footnotetext{
From the Department of Thoracic and Cardiovascular Surgery, WestGerman Heart Center Essen, University Hospital Essen, Essen, Germany,

Received for publication Feb 15, 2007; revisions received Feb 20, 2007 accepted for publication March 8, 2007.

Address for reprints: Prof Dr med H. Jakob, Direktor der Klinik, Klinik für Thorax- und Kardiovaskuläre Chirurgie, Westdeutsches Herzzentrum Essen, Germany (E-mail: heinz.jakob@uk-essen.de).

J Thorac Cardiovasc Surg 2007;134:244-5

$0022-5223 / \$ 32.00$

Copyright $\odot 2007$ by The American Association for Thoracic Surgery doi:10.1016/j.jtcvs.2007.03.023
}

$B)$. Then a straight cannula is inserted into the true lumen under direct vision, connected to the arterial line of the extracorporeal circuit, and open low-flow perfusion $(300-400 \mathrm{~mL} / \mathrm{min})$ is immediately started (Figure 2, A). While the lungs are being inflated manually, rapid deairing of the aortic arch and ascending aorta under direct visual control is possible, followed by oblique aortic crossclamping directly adjacent and tight to the arterial cannula. This allows rapid institution of full flow and cooling of the patient to the target core temperature, usually without the necessity of an additional pursestring suture fixation (Figure 2, B). This process takes less than 90 seconds. Now, the table is brought back to the horizontal plane and a left ventricular vent is placed via the right upper pulmonary vein. Crystalloid cardioplegic solution is applied directly into the coronary ostia and proximal repair of the aortic root is performed during cooling. After the target temperature has been reached, the crossclamp as well as the aortic cannula is removed and distal repair takes place.

\section{Discussion}

Retrograde perfusion via the femoral artery has been the perfusion mode of choice in thoracic aortic surgery including aortic dissection, with good results. ${ }^{2}$ However, many groups have moved to routine axillary artery cannulation to avoid potential malperfusion and atheroembolic complications associated with retrograde perfusion, especially in dissections. ${ }^{3,4}$ In cases of pericardial tamponade and life-threatening hemodynamic instability, the axillary approach sometimes is too time-consuming. Alternately, Wada and colleagues ${ }^{5}$ reported excellent results with transapical left ventricular cannulation across the aortic valve into the true lumen guided by transesophageal echocardiography.

Our policy has been to utilize axillary artery cannulation in all but extremely unstable situations and computed tomography-

\section{TABLE 1. Patient characteristics and outcome}

\begin{tabular}{lc}
\hline Patients, $\mathrm{n}$ & 8 \\
Age, y (mean \pm SD) & $56 \pm 14$ \\
Male/female, n & $4 / 4$ \\
Acute type A dissection, n & 8 \\
DeBakey I, n & 4 \\
DeBakey II, n & 4 \\
Emergency (<24 h), n & 8 \\
Cardiac tamponade, n & 3 \\
Cerebral malperfusion, n & 5 \\
Hospital mortality, n & 0 \\
Neurological dysfunction & \\
$\quad$ Permanent, n & 1 \\
Transient, n & 1 \\
\hline
\end{tabular}




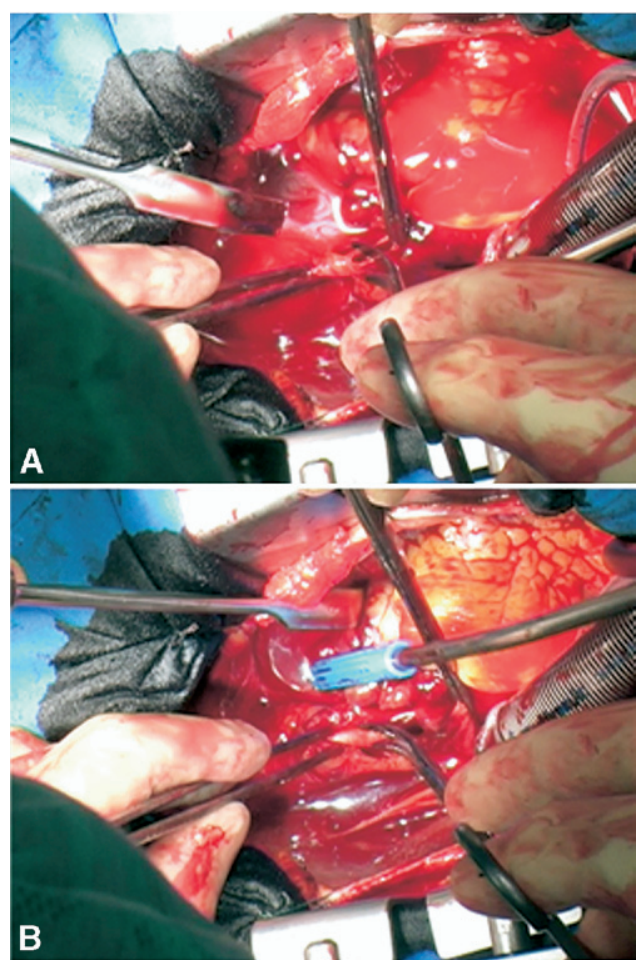

Figure 1. Incision of the false lumen (A) and true lumen (B).

proven dissection extending into the innominate artery. In those cases, direct cannulation of the ascending aorta after transesophageal echocardiographic demonstration of a free communication between the separated aortic layers has been performed. In contrast to Minatoya and colleagues, ${ }^{1}$ however, we experienced few cases of dismal neurologic outcome in nonmalperfusion patients. This experience prompted the reported modified direct cannulation technique of the ascending aorta. Inasmuch as all patients are preoxygenated with an inspired oxygen fraction of $100 \%$, a short "pressureless" period of less than 90 seconds most probably can be well tolerated. In conclusion, we propose that primary venous exsanguination and ascending aortic cannulation of the true lumen under direct vision with controlled deairing deserves serious consideration as a safe and rapid mode of antegrade arterial perfusion in very acute type A dissection.

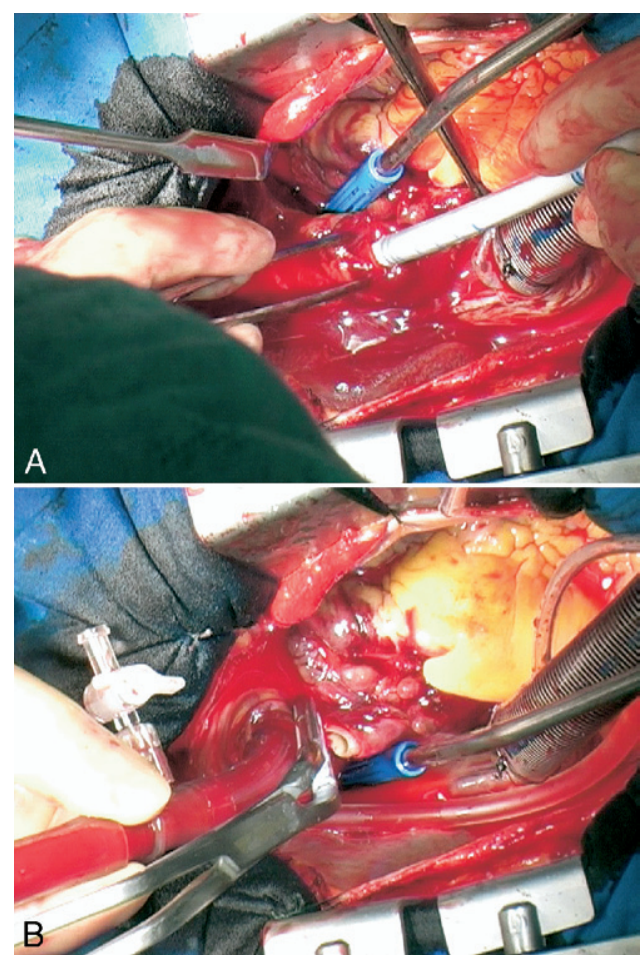

Figure 2. Open cannulation under visual control (A) and crossclamping (B).

\section{References}

1. Minatoya K, Karck M, Szpakowski E, Harringer W, Haverich A. Ascending aortic cannulation for Stanford type A acute aortic dissection: another option. J Thorac Cardiovasc Surg. 2003;125:952-3.

2. Fusco DS, Shaw RK, Tranquilli M, Kopf GS, Elefteriades JA. Femoral cannulation is safe for type A dissection repair. Ann Thorac Surg. 2004;78:1285-9.

3. Strauch JT, Spielvogel D, Lauten A, Lansman SL, McMurty K, Bodian $\mathrm{CA}$, et al. Axillary artery cannulation: routine use in ascending aorta and arch replacement. Ann Thorac Surg. 2004;78:103-8.

4. Budde JM, Serna DL, Osborne SC, Steele MA, Chen EP. Axillary cannulation for proximal aortic surgery is as safe in the emergent setting as in elective cases. Ann Thorac Surg. 2006;82:2154-60.

5. Wada S, Yamamoto S, Honda J, Hiramoto A, Wada H, Hosoda Y. Transapical aortic cannulation for cardiopulmonary bypass in type A aortic dissection operations. J Thorac Cardiovasc Surg. 2006;132: $369-72$. 